\title{
Outcomes measured by mortality rates, quality of life and degree of autonomy in the first year in stroke units in Spain
}

Javier Mar ${ }^{1,7^{*}}$, Jaime Masjuan ${ }^{2}$, Juan Oliva-Moreno ${ }^{3}$, Nuria Gonzalez-Rojas ${ }^{4}$, Virginia Becerra ${ }^{4}$, Miguel Ángel Casado ${ }^{5}$, Covadonga Torres ${ }^{5}$, María Yebenes ${ }^{5}$, Manuel Quintana ${ }^{6}$, Jose Alvarez-Sabín ${ }^{6}$, on behalf of CONOCES Investigators Group

\begin{abstract}
Introduction: The primary objective of this sub analysis of the CONOCES study was to analyse outcomes in terms of mortality rates, quality of life and degree of autonomy over the first year in patients admitted to stroke units in Spain. The secondary objective was to identify the factors determining good prognosis.

Methods: We studied a sample of patients who had suffered a confirmed stroke and been admitted to a Stroke Unit in the Spanish healthcare system. Socio-demographic and clinical variables and variables related to the level of severity (NIHSS), the level of autonomy (Barthel, modified Rankin) and quality of life (EQ-5D) were recorded at the time of admission and then three months and one year after the event. Factors determining prognosis were analysed using logistic regression and ROC curves.

Results: A total of 321 patients were recruited, 33\% of whom received thrombolytic treatment, which was associated with better results on the Barthel and the modified Rankin scales and in terms of the risk of death. Mean quality of life measured through EQ-5D improved from 0.57 at discharge to 0.65 one year later. Full autonomy level measured by Barthel index increased from $30.1 \%$ at discharge to $52.8 \%$ at one year and by the modified Rankin scale from $51 \%$ to $71 \%$. The rates for in-hospital and 1-year mortality were $5.9 \%$ and $17.4 \%$ respectively. Low NIHSS scores were associated with a good prognosis with all the outcome variables. The three instruments applied (NIHSS, Barthel and modified Rankin scales) on admission showed good discriminative ability for patient prognosis in the ROC curves.

Conclusions: There has been a change in the prognosis for stroke in Spain in recent years as the quality of life at 1 year observed in our study is clearly higher than that obtained in other Spanish studies conducted previously. Moreover, survival and functional outcome have also improved following the introduction of a new model of care. These results clearly promote extension of the model based on stroke units and reinforced rehabilitation to the majority of the more than 100,000 strokes that occur annually in Spain.
\end{abstract}

Keywords: Stroke, Outcomes, Disability, Quality of life, Stroke units, Thrombolysis

\footnotetext{
* Correspondence: javier.marmedina@osakidetza.net

${ }^{1}$ Clinical Management Service, Alto Deba Hospital, Mondragon, Spain

'Unidad de Gestión Sanitaria, Hospital 'Alto Deba', Avenida Navarra 16, 20500

Mondragón, Spain

Full list of author information is available at the end of the article
} 


\section{Introduction}

In the 20th century, specific treatment for stroke was mainly directed at primary prevention, with a particular focus on controlling risk factors like hypertension [1-3]. While patients were in hospital, the clinician's role was limited to maintaining vital functions and preventing complications [4]. The advent of thrombolysis and its successful use in acute myocardial infarction opened the way for an active approach to patient care, which led to the creation of stroke units [5-7]. At the same time the Stroke National Plan reinforced the key role of rehabilitation in the final outcome $[8,9]$. With this change in the model of care, it was recognised that the care received during hospitalisation and in the first year is a critical element in the prognosis of patients with stroke, both in terms of survival and functional status, and thus a determining factor in the resulting economic and social burden [7]. The new proactive approach enabled the previous fatalistic attitude to be overcome and led to improved outcomes through the incorporation of evidence-based therapies such as reperfusion and stroke units into the standard treatment [1,7-10]. Thus, the healthcare system placed emphasis on the characteristics of the different care levels with promotion of reference stroke hospitals, set up less restrictive stroke code activation criteria that included new therapeutic options, established new standard measures for endovascular treatment, reinforced the rehabilitation process and developed tele-medicine stroke networks $[8,9]$.

Current demographic trends towards aging mean that measurement of the burden of disease has had to give greater priority to diseases which, in addition to causing mortality, also generate disability $[11,12]$. As a result, health-related quality of life (HRQOL) has become a key element when measuring outcomes of medical interventions $[13,14]$. However, most of the studies carried out in Spain on the impact of stroke on HRQOL are dated from several years ago [15-17]. It is therefore necessary to measure the impact that the widespread introduction of stroke units has had on patients' HRQOL and level of autonomy, in order to assess the improvements made to secondary and tertiary stroke prevention [18].

The primary objective of this part of the CONOCES study [19] was to analyse outcomes in terms of mortality rates, health-related quality of life (HRQOL) and degree of autonomy in patients admitted to stroke units in Spain over the first year after admission. The secondary objective was to identify the factors determining good outcome.

\section{Methods}

\section{Type of study and design}

CONOCES was a prospective, observational, epidemiological, naturalistic, multicentre study of costs and outcomes of the disease in the Spanish healthcare setting in a sample of patients who had suffered a confirmed stroke [19]. The inclusion criteria were: being over 18 years of age; confirmed clinical diagnosis of first ischaemic or haemorrhagic stroke within 24 hours of onset; admission to a stroke unit; voluntary participation in the study; and signed informed consent by the patient and/or their primary caregiver. During the recruitment phase patients who met the inclusion criteria were enrolled consecutively in the study in all the participant centres. The study variables were collected by the medical team through personal interviews with the patient and the primary caregiver during the hospital stay in the stroke units and at the follow-up visits at 3 and 12 months. In the first data collection all the autonomy and quality of life scales were recorded at hospital discharge. Only the mRS was also recorded at admission. The protocol was approved by the Ethics Committee of Hospital Clínic i Provincial de Barcelona.

The variables were socio-demographic (age, gender and residence) and clinical (activation of stroke proto$\mathrm{col}$, time to neurological care, aetiology, recurrence, presence of atrial fibrillation (AF), thrombolytic therapy and death during the follow-up period) in nature. HRQOL and degree of autonomy, as well as their determining factors, were also measured by determining neurological status on admission using the National Institutes of Health Stroke Scale (NIHSS) [20] and by assessing the patients' disability by measuring functional status with the Barthel Index (BI) [21] and degree of functional dependence with the modified Rankin Scale (mRS) at discharge, three months and one year [22]. BI and mRS are the most commonly used measurement scales to assess the level of autonomy of stroke patients. mRS has become the most widely used clinical outcome measure for stroke in clinical trials. The scale ranks from 0 to 6 , from perfect health with no symptoms to death [22]. Although the mRS classifies deaths in category 6 , we decided to exclude them from the functional status analyses. BI is an ordinal scale used to measure performance in daily living activities. Each performance item is rated on this scale with a given number of points assigned to each level or ranking. It uses ten variables to describe mobility, feeding, toilet use, dressing, bathing, faecal and urinary incontinence, help needed with grooming and other activities. A higher number is associated with a greater likelihood of being able to live at home with a degree of independence following discharge from hospital. Each item can score 0, 5 or 10 points, so that BI score range from 0 to 100 , corresponding to five levels of dependence: independent (100 points), low dependence (91-99 points), moderate dependence (61-90 points), severe dependence (21-60 points), total dependence $(0-20)[21,23]$. NIHSS has become the most widely-used scale to assess initial neurological status, in the follow-up of patients on treatment 
and also for routine clinical monitoring in stroke units $[24,25]$. It is composed of 11 items, each of which scores a specific ability between 0 and 4 . For each item, a score of 0 typically indicates normal function in that specific ability, while a higher score is indicative of some level of impairment. The individual scores from each item are summed in order to calculate a patient's total NIHSS score. The maximum possible score is 42 , with the minimum score being 0 [24,25].

HRQOL was measured using the generic questionnaire EuroQuol (EQ-5D) at the same three time points [26]. The EQ-5D questionnaire was completed by the patients at the scheduled follow-up visits for the study. EQ-5D is a standardised instrument to measure self-reported health status with respect to five dimensions (mobility, self-care, usual activities, pain/discomfort, anxiety/depression) and three levels of severity (no problems, some or moderate problems, and extreme problems). It is characterised by the fact that it provides a single index value for each health state which can have a value of 1 or less, where 1 is equivalent to full health and 0 is death. These were normalised using conversion tables obtained in the general Spanish population [27]. When the patient was unable to communicate, the interviewer conducted the test to a close relative or caregiver [28].

\section{Statistical analysis}

Statistical differences in the comparison of contingency tables were analysed using the chi-square test, taking a value of $\alpha$ equal to or less than 0.05 . Given that the variables are not normally distributed, the Wilcoxon test was used to measure the statistical significance of differences between means, as with ordinal data. All statistical analyses were carried out using SPSS software (version 21; SPSS Inc., Chicago, IL).

To analyse the magnitude of the observed change in the quality of life, the value of the final EQ-5D was compared with the original and with a sample of general population over 65 using the effect size [29]. The EQ-5D sample used to describe general population characteristics proceeded from a random sample of general population from the Canary Islands [30] which mean score was 0.73 and standard deviation 0.32 . Cohen defined as nonsignificant an effect size of less than 0.2 , an effect size between 0.2 and 0.5 as small, between 0.5 and 0.8 as moderate, and greater than 0.8 as large [29].

To analyse the association of clinical variables on admission with functional capacity and HRQOL after a year, statistical logistic regression analyses were performed in which the dependent variables were mortality, the value 1 in EQ-5D, modified Rankin Scale level 0-2, Barthel below 61 (total or severe dependence) and Barthel 100. The independent variables were age, gender, arrival time to neurological care, aetiology (ischaemic or haemorrhagic), AF, NIHSS, hospital arrival time and thrombolytic therapy (yes/no). The likelihood of receiving thrombolytic therapy was further investigated in a logistic regression model in which the explanatory variables were age, gender, NIHSS and the time of arrival.

Furthermore, we used an approach based on the analysis of ROC (Receiver Operating Characteristic) curves to measure sensitivity to change. This allowed us to assess the ability of the instruments used on admission, such as the NIHSS, the mRS and the BI, to detect patients with good prognosis, using the same methodology that is used to determine whether or not a diagnostic test identifies the condition of interest [31]. The ROC curve is obtained by plotting sensitivity for each breakpoint on the $y$-axis and its corresponding 1-specificity on the $\mathrm{x}$-axis. If the instrument is sensitive, it has an ROC curve where sensitivity peaks have associated minimum values of 1 -specificity. Conversely, if the instrument is insensitive, it has an ROC curve near to the reference line (line dividing the axis into two equal parts, which indicates the minimum level of discrimination). To characterise the instrument as discriminant, areas greater than $70 \%$ are required. The statistical method also calculated the statistical significance of the curve.

\section{Results}

A total of 321 patients were enrolled in the study between November 2010 and May 2011. Eight patients were lost to follow-up between discharge and the 3month visit, and a further 7 by 12 months. The mean age was 72.1 years (SD 13.2) and 176 patients (54.8\%) were male. The main socio-demographic and clinical characteristics of the sample are shown in Table 1. We should highlight that $33 \%$ of patients received thrombolytic therapy. The rates for in-hospital and 1-year mortality were $5.9 \%$ and $17.4 \%$ respectively.

The level of autonomy and quality of life from admission to one year later improved on all scales (Table 2). The percentage of category 3 (no problems) in the dimensions of the EQ-5D increased across the board. Figure 1 shows how functional level evolved according to the BI from admission to 12 months. The effect size for EQ-5D obtained from hospital discharge to 12 months was small $(0.25)$. When we compared the EQ-5D values of general population with the mean value at 12 months the same effect size was attained. However the Visual Analogic Scale scores did not show any statistically significant differences between the admission and after one year.

In the univariate analysis (Table 3), age, NIHSS on admission and the presence of $\mathrm{AF}$ appear as variables statistically associated with level of autonomy (Barthel and modified Rankin scores at 1 year). In contrast, aetiology, thrombolysis and time of arrival are not statistically significant. Male gender is statistically associated with a 
Table 1 Socio-demographic and clinical characteristics of the patients

\begin{tabular}{|c|c|c|}
\hline Age in years & Mean (SD) & $72.1(13.2)$ \\
\hline Gender & Value & $(\%)$ \\
\hline Male & 176 & 54.8 \\
\hline Female & 145 & 45.2 \\
\hline Living Environment & Value & $\%$ \\
\hline Home & 316 & 98.4 \\
\hline Residential Care for the Elderly & 3 & 0.9 \\
\hline Other & 2 & 0.6 \\
\hline Stroke Protocol Activated & Value & $\%$ \\
\hline No & 147 & 45.8 \\
\hline Yes & 167 & 52 \\
\hline Time to neurological care & Frequency & Percentage \\
\hline $0-1.5$ hours & 71 & 22.7 \\
\hline $1.5-3$ hours & 94 & 30 \\
\hline 3-4.5 hours & 34 & 10.9 \\
\hline$>4.5$ hours & 114 & 36.4 \\
\hline Type of stroke & Value & $\%$ \\
\hline Cerebral Infarction & 291 & 90.7 \\
\hline Haemorrhage & 30 & 9.3 \\
\hline Stroke recurrence at 1 year & Value & $\%$ \\
\hline Yes & 25 & 7.8 \\
\hline No & 296 & 92.2 \\
\hline Atrial Fibrillation & Value & $\%$ \\
\hline Yes & 161 & 50.2 \\
\hline No & 160 & 49.8 \\
\hline Thrombolysis total & Value & $\%$ \\
\hline Yes & 106 & 33.0 \\
\hline No & 215 & 67.0 \\
\hline Thrombolysis NIHSS 6-42 & Value & $\%$ \\
\hline Yes & 92 & 50.8 \\
\hline No & 89 & 49.2 \\
\hline Thrombolysis NIHSS 0-5 & Value & $\%$ \\
\hline Yes & 14 & 10.0 \\
\hline No & 126 & 90.0 \\
\hline Death while in hospital & Value & $\%$ \\
\hline Yes & 19 & 5.9 \\
\hline No & 302 & 94.1 \\
\hline Death during the year of study & Value & $\%$ \\
\hline Yes & 56 & 17.4 \\
\hline No & 265 & 82.6 \\
\hline NIHSS on admission & Value & $\%$ \\
\hline Minor strokes (1-3) & 86 & 26.8 \\
\hline Moderate strokes (4-10) & 114 & 35.5 \\
\hline Severe strokes $(>10)$ & 121 & 37.7 \\
\hline
\end{tabular}

NIHSS: National Institute of Health Stroke Scale.
Barthel scale score of 100 but not with a modified Rankin between 0 and 2 .

The results of logistic regression analysis are presented in Table 4 and show that low NIHSS is associated with good prognosis for all outcome variables. Being under the age of 75 was only associated with a better outcome for mortality and low modified Rankin score. Males had better quality of life and increased autonomy in terms of Barthel 100. Although in the univariate analysis the prognosis in patients treated with thrombolysis was found to be no different (Table 3), in the logistic regression, this treatment appears to be associated with better outcome for the Barthel and modified Rankin scores and the risk of death (Table 4). The reason for this difference is the distribution of patients according to NIHSS and thrombolysis, as half of the patients who were in the 6-42 group of the NIHSS received thrombolytic therapy while only $10 \%$ of those in the $0-5$ group did so (Table 1).

The explanatory logistic regression of the probability of thrombolysis showed statistically significant values for a mild NIHSS (OR 8.3) and time of arrival less than 3 hours (OR 9.5). No statistically significant associations were found with age or gender. The ROC curves reached areas under the curve above $70 \%$ and statistical significance levels below 0.05 for the three instruments used on admission (NIHSS, Barthel and modified Rankin scales) (Table 5 and Figure 2).

\section{Discussion}

The main conclusion from the results of this study is that the prognosis of stroke in Spain has changed in recent years. Both survival and functional outcome have improved as a result of the introduction of a new model of care $[18,32]$. This new model, based on stroke units, thrombolysis, physical therapy and secondary prevention, has been promoted by the stroke strategy of the Spanish National Health Service in coordination with regional health authorities and healthcare professionals $[8,9]$.

The in-hospital mortality rate $(5.9 \%)$ is well below the $10 \%$ reported in 2006 in the U.S [32]. Compared to the $30 \%$ 1-year mortality rate described in the literature, this figure has dropped to $18.3 \%[18,32]$. Also striking is the sequence of disability-scale measurements that shows a functional recovery process in which good levels of autonomy (0-2 on the modified Rankin scale) increase from $51 \%$ at discharge from hospital to $71 \%$ in the survivors at 1 year. These good results after discharge show that the development of post-stroke rehabilitation and the inclusion of physical therapy in the Spanish Stroke Plan improved the prognosis $[8,9]$.

Thrombolytic therapy is a good prognostic factor, as treated patients were found to have statistically significant OR above 2 in the Barthel and modified Rankin scales in 
Table 2 Changes in level of autonomy and quality of life scales from hospital admission up to 1 year later

\begin{tabular}{|c|c|c|c|c|}
\hline & Previous & Discharge & 3 months & 12 months \\
\hline Modified rankin scale & N (\%) & $\mathrm{N}(\%)$ & $\mathrm{N}(\%)$ & N (\%) \\
\hline From 0 to 2 & 299 (93.7\%) & $165(54.6 \%)$ & $186(67.1 \%)$ & $182(71.1 \%)$ \\
\hline Above 2 & $20(6.3 \%)$ & $137(45.4 \%)$ & 91 (32.9\%) & $68(28.9 \%)$ \\
\hline Barthel & & N (\%) & N (\%) & N (\%) \\
\hline Independent (100) & & $91(28.3 \%)$ & $130(40.5 \%)$ & $132(41.1 \%)$ \\
\hline Low dependence (91-99) & & $11(3.4 \%)$ & $22(6.9 \%)$ & $17(5.3 \%)$ \\
\hline Moderate dependence (61-90) & & $93(29.0 \%)$ & $55(17.1 \%)$ & $50(15.6 \%)$ \\
\hline Severe dependence (21-60) & & $57(17.8)$ & $48(15.0 \%)$ & $32(10.0 \%)$ \\
\hline Total dependence (0-20) & & $50(15.6 \%)$ & $23(7.2 \%)$ & 19 (5.9\%) \\
\hline Cumulative deaths & & 19 (5.9\%) & 35 (10.9\%) & $56(17.4 \%)$ \\
\hline EQ-5D & & Discharge & 3 months & 12 months \\
\hline Utilities mean (SD) & & $0.57(0.32)$ & $0.62(0.30)$ & $0.65(0.28)$ \\
\hline Visual Analogic Scale mean (SD) & & $45.81(28.62)$ & $44.15(31.56)$ & $45.74(33.36)$ \\
\hline Number of responses & & 274 & 261 & 234 \\
\hline EQ-5D dimensions & & $\mathrm{N}(\%)$ & N (\%) & N (\%) \\
\hline \multirow[t]{3}{*}{ Mobility } & No problems & $122(44.2 \%)$ & $137(52.5 \%)$ & $123(52.1 \%)$ \\
\hline & Some problems & $100(36.2 \%)$ & $98(37.5 \%)$ & $100(42.4 \%)$ \\
\hline & Confined to bed & $54(19.6 \%)$ & $26(10.0 \%)$ & $13(5.5 \%)$ \\
\hline \multirow[t]{3}{*}{ Personal care } & No problems & $137(49.8 \%)$ & $156(59.8 \%)$ & $155(67.7 \%)$ \\
\hline & Some problems & $75(27.3 \%)$ & $36(13.8 \%)$ & $52(22.0 \%)$ \\
\hline & Unable & $63(22.9 \%)$ & 69 (26.4\%) & $29(12.3 \%)$ \\
\hline \multirow[t]{3}{*}{ Activity } & No problems & $83(30.1 \%)$ & $116(44.4 \%)$ & $116(49.2 \%)$ \\
\hline & Some problems & $122(44.2 \%)$ & 44 (16.9\%) & $84(35.6 \%)$ \\
\hline & Unable & $71(25.7 \%)$ & $101(38.7 \%)$ & $36(15.3 \%)$ \\
\hline \multirow[t]{3}{*}{ Pain } & No pain & $171(62.4 \%)$ & $159(60.9 \%)$ & 140 (59.3\%) \\
\hline & Moderate pain & $94(34.3 \%)$ & 88 (33.7\%) & $86(36.4 \%)$ \\
\hline & Extreme pain & $9(3.3 \%)$ & $14(5.4 \%)$ & $10(4.2 \%)$ \\
\hline \multirow[t]{3}{*}{ Anxiety } & Not anxious & $153(55.8 \%)$ & $131(50.2 \%)$ & $134(56.8 \%)$ \\
\hline & Moderately anxious & $103(37.6 \%)$ & $102(39.1 \%)$ & 89 (37.7\%) \\
\hline & Extremely anxious & $18(6.6 \%)$ & $28(10.7 \%)$ & $13(5.5 \%)$ \\
\hline Cumulative losses & & 0 & 8 & 15 \\
\hline
\end{tabular}

survival. Among the factors that have changed from 10-15 years ago is the time to arrival at hospital, with the median dropping from 6 hours to 3 hours. Along with stroke unit care, this explains why a third of patients received thrombolysis. Multivariate analysis made it possible to see its association with better prognosis despite the NIHSS variable acting as a confounding factor. A low NIHSS score generally corresponds to patients with neurological deficit that is only slightly disabling, and is one of the exclusion criteria in summaries of product characteristics to avoid the risk of bleeding. However, these results and those from a recent clinical trial have led to a rethink, as it is known that not all cases with low NIHSS have a good outcome [33].
In the analysis of factors influencing prognosis, as in other studies, the NIH stroke severity scale stands out [34]. Patients with low admission NIHSS show good prognosis, OR 3 to 7 times higher according to the outcome variable. Younger age is associated with a good prognosis at 1 year on the mRS and for mortality but not with the BI and the EQ-5D. Men have better prognosis when the outcome is measured with the BI and the EQ-5D. The EQ-5D results may be due to the fact that this difference is also found when analysing the general population [28]. Studies suggest that in general, the poorer HRQOL reported in older women is mainly due to a higher prevalence of disability and chronic 


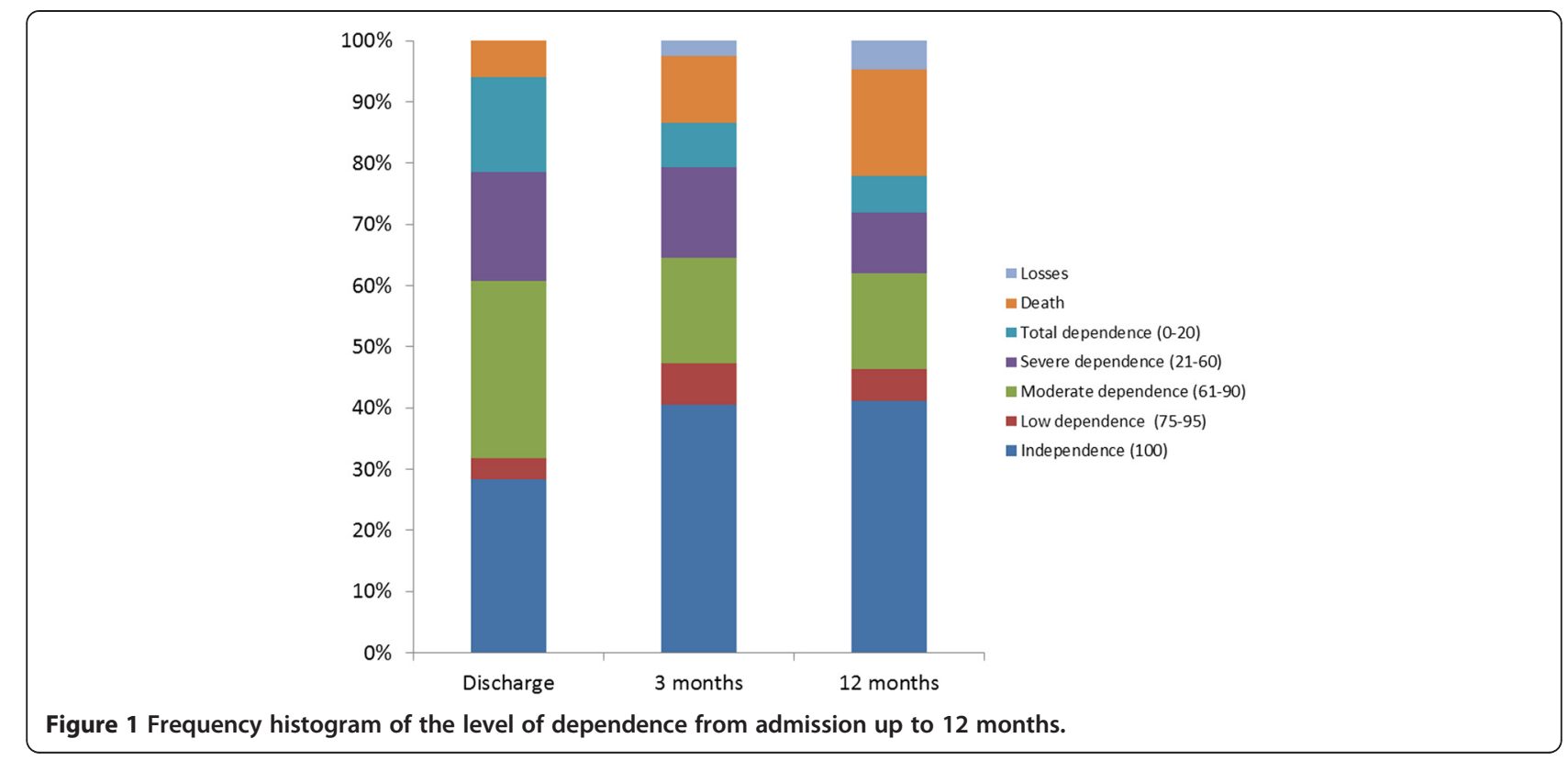

diseases [35]. When quality of life was measured by the Visual Analogic Scale the results were near the same in the three measurements. This lack of sensitivity to change can be attributed to the limited validity of the thermometer to identify the preferences of stroke patients.

The quality of life at 1 year observed in our study is clearly higher $(0.65)$ than that obtained in other Spanish studies conducted in 2000 and 2004 in which the average values were 0.49 and 0.50 respectively [16,36]. In the comparison of the characteristics of our sample with both studies we see that age and sex distributions were similar (mean age 72 years was and $55 \%$ of males). However the percentage of haemorrhages was lower in our study. As the sample sizes in both studies were small we need to be cautious to draw conclusions but it seems plausible that the changes found in terms of improved time to arrival at hospital, thrombolysis, rehabilitation and stroke units have had a direct bearing on the improvement in HRQOL. Despite these changes, the general population over age 65 still has an HRQOL 11\% higher than the sample of patients with stroke. This difference, which can be interpreted as a clinically significant difference as it exceeds the range of 0.074 to 0.080 cited in the literature [37,38], reminds us that much more can still be done to minimise the functional impact of stroke. What is important is that many patients who suffer stroke have a very low HRQOL as a result of the loss of functional autonomy, and responding to this problem continues to be a challenge for public health [37]. The effect size of the intervention from discharge to the year is small according to the Cohen criteria [30]. However it is an important element to measure because it allows monitoring of the impact of tertiary stroke prevention. As the sample included some aphasic patients who were unable to communicate, the use of proxies

Table 3 Distribution of variables for level of autonomy at 12 months according to clinical characteristics

\begin{tabular}{|c|c|c|c|c|c|c|}
\hline & \multicolumn{3}{|l|}{ Barthel } & \multicolumn{3}{|c|}{ Modified rankin scale } \\
\hline & 100 & $0-95$ & $\mathrm{p}$ & $\overline{0-2}$ & $3-5$ & $\mathrm{p}$ \\
\hline Gender (Male) & $87(65.9 \%)$ & $52(44.1 \%)$ & 0.001 & $107(58.8 \%)$ & $32(47.1 \%)$ & NS \\
\hline Age $<75$ years & $86(65.2 \%)$ & $58(49.2 \%)$ & 0.015 & $26(38.2 \%)$ & $118(64.8 \%)$ & 0.015 \\
\hline NIHSS on admission $>5$ & $50(37.9 \%)$ & $77(65.3 \%)$ & $<0.001$ & $74(40.7 \%)$ & $53(77.9 \%)$ & $<0.001$ \\
\hline Infarction vs. Haemorrhage & $120(90.9 \%)$ & $106(89.8 \%)$ & NS & $165(90.7 \%)$ & $61(89.7 \%)$ & NS \\
\hline Thrombolysis & $42(31.8 \%)$ & 40 (33.9\%) & NS & $57(31.3 \%)$ & $25(36.8 \%)$ & NS \\
\hline Arrival time $<3 \mathrm{~h}$ & $66(51.2 \%)$ & $59(51.8 \%)$ & NS & $90(50.6 \%)$ & $35(53.8 \%)$ & NS \\
\hline Atrial Fibrillation & $52(39.4 \%)$ & $64(54.2 \%)$ & 0.022 & $76(41.8 \%)$ & $40(58.8 \%)$ & 0.022 \\
\hline
\end{tabular}

NIHSS: National Institute of Health Stroke Scale. 
Table 4 Results from logistic regressions relating the characteristics of stroke patients and the 1-year outcome

\begin{tabular}{|c|c|c|c|c|c|c|c|c|c|c|}
\hline & \multicolumn{2}{|c|}{ Barthel 100} & \multicolumn{2}{|c|}{ mRS 0-2 } & \multicolumn{2}{|c|}{ EQ-5D 1} & \multicolumn{2}{|c|}{ Barthel $<60$} & \multicolumn{2}{|c|}{ Death } \\
\hline & $p$ & OR & $p$ & OR & $p$ & OR & $p$ & OR & $p$ & OR \\
\hline Haemorrhage & NS & & NS & & 0.046 & 0.261 & NS & & NS & \\
\hline Atrial Fibrillation & NS & & NS & & NS & & NS & & NS & \\
\hline Age over 75 & NS & & 0.001 & 0.335 & NS & & NS & & 0.000 & 6.196 \\
\hline NIHSS (0-5) & 0.000 & 3.882 & 0.000 & 6.985 & 0.010 & 2.769 & 0.000 & 0.234 & 0.000 & 0.201 \\
\hline Male & 0.007 & 2.137 & NS & & 0.005 & 2.723 & NS & & NS & \\
\hline Thrombolysis & 0.047 & 2.173 & 0.036 & 2.540 & NS & & NS & & 0.006 & 0.307 \\
\hline Arrival time & NS & & NS & & NS & & NS & & NS & \\
\hline
\end{tabular}

mRS: modified Rankin Scale. OR: Odds ratio. NIHSS: National Institute of Health Stroke Scale.

was a limitation that we need to notice. The benefits of including proxy responses outweigh the loss of information that occurs when those patients are excluded, because the most impaired group is a key component of the prevalent stroke population [28].

The gender analyses can be interpreted as stroke units having reduced gender inequalities in care for stroke patients. We did not find the association between being female and higher mortality rates which has been reported by other studies [39] and there is no gender distinction in access to thrombolysis. The differences found in quality of life have also been described in the general population $[30,35]$.

The age-standardised mortality rates for stroke have fallen worldwide over the past two decades [13]. However, despite this improvement in the epidemiological profile, we must not forget that stroke still represents one of the leading causes of death and disability. The absolute number of strokes, the prevalence of associated disability, the related deaths and the total global burden are large and have not come down $[40,41]$. Challenges remain, such as raising the percentage of patients receiving thrombolysis and controlling risk factors like hypertension or atrial fibrillation. The proportion of patients receiving thrombolytic treatment is very high (33\%) but can still be improved. Identification of thrombolysis as a factor associated with good prognosis provides an incentive to maintain the goal of improving public awareness of stroke as a medical emergency. Additional options for this are the increased time window for thrombolysis and generalisation of endovascular treatment.

The three instruments applied on admission (NIHSS, Barthel and modified Rankin scales) showed good discriminating characteristics with measurements of good prognosis. In all cases the AUC exceeded $70 \%$ and tests of significance were statistically significant. Their use may make it possible to predict the functional outcome and thus help patients and families to prepare their response to the new social needs.

Quality indicators are currently collected in different European countries to monitor in the real world the quality of care received by stroke patients [42]. However, the huge variety in measuring the performance of stroke care hampers comparisons [43]. In the same line, our results describe how successful has been the implementation of strategies found effective in clinical trials when applied to Spanish hospitals.

Given that we did not include patients hospitalised in departments without stroke units, these results are not representative of all the Spanish stroke population. Thus, as a limitation we notice that these results are valid only for the percentage of stroke patients that are admitted into a stroke unit [44]. This figure has increased during the last years allowing the patients to receive a specific and proactive treatment. However, this study shows that decision-makers need to follow the recommendations from the Spanish Stroke Plan to

Table 5 Area under the curve and significance values for the ROC curves measuring the discriminatory capacity of the instruments applied on admission with outcome at 1 year

\begin{tabular}{|c|c|c|c|c|c|c|c|c|c|c|}
\hline \multirow{2}{*}{$\frac{\text { 1-year outcome }}{\text { Instrument on admission }}$} & \multicolumn{2}{|c|}{ Barthel $=100$} & \multicolumn{2}{|c|}{ Rankin 0-2 } & \multicolumn{2}{|c|}{ EQ-5D } & \multicolumn{2}{|c|}{ Barthel $<60$} & \multicolumn{2}{|c|}{ Death 1 year } \\
\hline & AUC & $\mathrm{p}$ & AUC & $\mathrm{p}$ & AUC & $\mathrm{p}$ & AUC & $\mathrm{p}$ & AUC & $\mathrm{p}$ \\
\hline NIHSS & 0.677 & 0.000 & 0.717 & 0.000 & 0.670 & 0.000 & 0.671 & 0.000 & 0.765 & 0.000 \\
\hline Barthel & & & 0.856 & 0.000 & 0.718 & 0.000 & & & 0.835 & 0.000 \\
\hline modified Rankin & 0.779 & 0.000 & & & 0.737 & 0.000 & 0.598 & 0.028 & 0.811 & 0.039 \\
\hline
\end{tabular}

AUC: area under the curve. p: statistical significance value. 


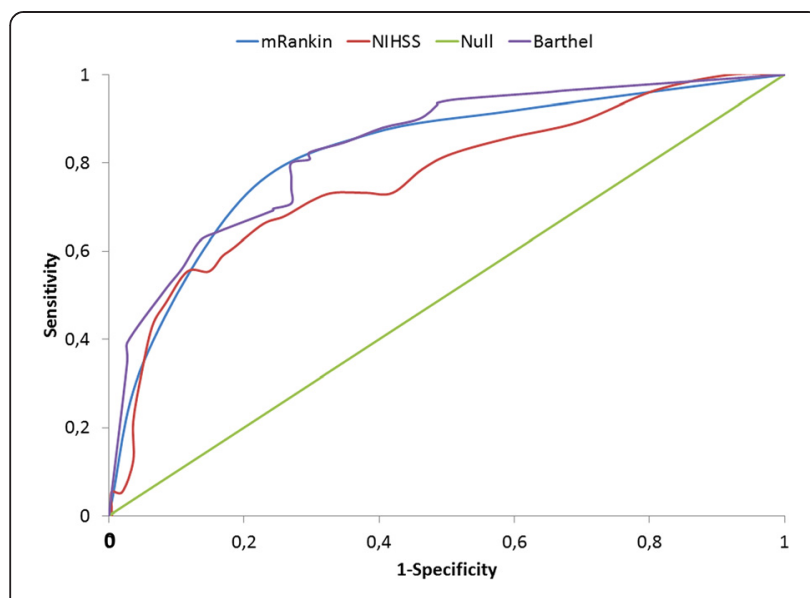

Figure 2 ROC curves measuring the discriminatory capacity of the modified Rankin, NIHSS and Barthel instruments applied on admission with the prognosis of 1-year mortality. NIHSS:

National Institute of Health Stroke Scale.

benefit all the population and clearly promoting extension of the model to the majority of the more than 100,000 strokes that occur annually in Spain [45]. Expanding the coverage can be achieved by increasing the number of stroke units or through the use of telemedicine systems which allow the new techniques to be implemented even in rural areas where the population has poor access to tertiary hospitals such as those included in this study [46].

\section{Abbreviations \\ CONOCES: Costs and outcomes multicentre study of stroke patients admitted to a Stroke Unit in Spain; HRQOL: Health-related quality of life; NIHSS: National Institutes of Health Stroke Scale; ROC: Receiver operating characteristic.}

\section{Competing interests}

Advisor researchers (José Álvarez-Sabín, Jaime Masjuan, Javier Mar and Juan Oliva-Moreno) have received honoraria from Boehringer Ingelheim Spain for their participation in this study.

Covadonga Torres, Miguel Ángel Casado and María Yébenes work in PORIB, the firm responsible for the study management.

Nuria González-Rojas works for Boehringer Ingelheim Spain. Virginia Becerra worked for Boehringer Ingelheim Spain at the time of the study.

\section{Authors' contributions}

José Alvarez-Sabin, Jaime Masjuan, Javier Mar and Juan Oliva-Moreno conceived and designed the research. The CONOCES Investigators Group acquired, analysed and interpreted the data. Javier Mar, Covadonga Torres, Miguel Ángel Casado and María Yébenes performed the statistical analyses, interpreted the data and critically revised the manuscript for important intellectual content. Nuria González-Rojas and Virginia Becerra designed the research, interpreted the data, handled funding and supervision, and critically revised the manuscript for important intellectual content. Javier Mar, Manuel Quintana and José Alvarez-Sabin drafted the manuscript and critically revised the manuscript for important intellectual content. All authors read and approved the final manuscript.

\section{Acknowledgements}

The study has been funded by an unrestricted grant from Boehringer Ingelheim Spain.

\section{Annex 1: CONOCES Investigators Group}

INVESTIGATOR; HOSPITAL

Juan Francisco Arenillas Lara; Hospital Clínico Universitario de Valladolid. Maite Martínez Zabaleta; Hospital Donostia.

Mariano Rebollo Álvarez-Amandi; Hospital Universitario Marqués de Valdecilla.

Tomás Segura Martín; Hospital General de Albacete.

Aida Lago Martín; Hospital Universitario la Fe.

Jaime Gállego Culleré; Hospital de Navarra.

Juan Ignacio López Gastón; Hospital Universitario Miguel Servet.

Francisco Moniche Álvarez / Ma Dolores Jiménez; Hospital Virgen del Rocío.

José Castillo Sánchez; Hospital Clínico de Santiago de Compostela.

Ma Carmen Jiménez Martínez; Complejo Asistencial Son Espases.

Juan Carlos López Fernández; Complejo Hospitalario Dr. Negrín.

Ignacio Casado Naranjo; Complejo Hospitalario de Cáceres.

Carmen González Rodríguez; Hospital de Cabueñes.

Bernardo Escribano Soriano; Hospital Universitario Virgen de la Arrixaca.

\section{Author details}

${ }^{1}$ Clinical Management Service, Alto Deba Hospital, Mondragon, Spain. ${ }^{2}$ Stroke Unit, Neurology Department, Hospital Universitario Ramón y Cajal. Universidad de Alcalá, Madrid, Spain. ${ }^{3}$ Department of Economic Analysis, Universidad de Castilla La Mancha and REDISSEC, Toledo, Spain. ${ }^{4}$ Health Economics and Outcomes Research, Boehringer Ingelheim España, Barcelona, Spain. ${ }^{5}$ Pharmacoeconomics \& Outcomes Research Iberia, Madrid, Spain. ${ }^{6}$ Neurovascular Unit, Department of Neurology, Universitat Autònoma de Barcelona, Hospital Vall d'Hebron, Barcelona, Spain. Unidad de Gestión Sanitaria, Hospital 'Alto Deba', Avenida Navarra 16, 20500 Mondragón, Spain.

Received: 9 October 2014 Accepted: 3 March 2015

Published online: 17 March 2015

\section{References}

1. Biller J, Love BB. Nihilism and stroke therapy. Stroke. 1991;22:1105-7.

2. Adams HP, Kassell NF, Mazuz H. The patient with transient ischemic attacks. Is this time for a new therapeutic approach? Stroke. 1984;15:371-5.

3. Straus SE, Majumdar SR, McAlister FA. New evidence for stroke prevention: scientific review. JAMA. 2002;288:1388-95.

4. Goldberg G, Berger GG. Secondary prevention in stroke: a primary rehabilitation concern. Arch Physical Med Rehabilitation. 1988;69:32-40.

5. Fibrinolytic Therapy Trialists' (FTT) Collaborative Group. Indications for fibrinolytic therapy in suspected acute myocardial infarction: collaborative overview of early mortality and major morbidity results from all randomised trials of more than 1000 patients. Lancet. 1994;343:311-22.

6. The National Institute of Neurological Disorders and Stroke rt-PA Stroke Study Group. Tissue plasminogen activator for acute ischemic stroke. N Engl J Med. 1995;333:1581-7.

7. Brott T, Bogousslavsky J. Drug therapy: treatment of acute ischemic stroke. N Engl J Med. 2000;343:710-22.

8. Álvarez-Sabín J, Alonso de Leciñana M, Gallego J, Gil Peralta A, Casado I, Castillo J, et al. Plan de atención sanitaria del ictus. Neurologia. 2006;21:717-26.

9. Masjuan J, Álvarez-Sabín J, Arenillas J, Calleja S, Castillo J, Dávalos A, et al. Plan de asistencia sanitaria al ictus ii. 2010. Neurologia. 2011;26:383-96.

10. Stroke Unit Trialists' Collaboration. Organised inpatient (stroke unit) care for stroke. Cochrane Database of Syst Rev. 2013. Issue 9. Art. No.: CD000197. doi:10.1002/14651858.CD000197.pub3.

11. Knapp M, Prince M. Dementia UK: The Full Report. London: Alzheimer's Society; 2007.

12. Rothwell PM. The high cost of not funding stroke research: a comparison with heart disease and cancer. Lancet. 2001;357:1612-6.

13. Feigin $\mathrm{VL}$, Forouzanfar $\mathrm{MH}$, Krishnamurthi R, et al. Global and regional burden of stroke during 1990-2010: findings from the Global Burden of Disease Study 2010. Lancet. 2014;383:245-54.

14. Catalá-López F, García-Altés A, Alvarez-Martín E, Gènova-Maleras R, Morant-Ginestar C, Parada A. Burden of disease and economic evaluation of healthcare interventions: are we investigating what really matters? BMC Health Serv Res. 2011;11:75

15. Carod-Artal FJ. Medición de la calidad de vida en supervivientes de un ictus. Rev Neurol. 1999;29:447-56. 
16. Lopez-Bastida J, Oliva Moreno J, Worbes Cerezo M, Perestelo Perez L, Serrano-Aguilar P, Montón-Álvarez F. Social and economic costs and health-related quality of life in stroke survivors in the Canary Islands, Spain. BMC Health Serv Res. 2012;12:315.

17. Mar J, Arrospide A, Begiristain JM, Larrañaga I, Elosegui E, Oliva-Moreno J. The impact of acquired brain damage in terms of epidemiology, economics and loss in quality of life. BMC Neurol. 2011;11:46.

18. Hankey GJ. Stroke Treatment and Prevention: an Evidence-Based Approach. New York: Cambridge University Press; 2005.

19. Mar J, Álvarez-Sabín J, Oliva J, Becerra V, Casado MÁ, Yébenes M, et al. The costs of stroke in Spain by aetiology: the CONOCES study protocol. Neurologia. 2013;28:332-9.

20. Brott T, Marler JR, Olinger CP, Adams Jr HP, Tomsick T, Barsan WG, et al. Measurements of acute cerebral infarction: lesion size by computed tomography. Stroke. 1989;20:871-5.

21. Mahoney Fl, Barthel DW. Functional evaluation: the Barthel index. Md Med J. 1965;14:61-5.

22. van Swieten JC, Koudstaal PJ, Visser MC, Schouten HJ, van Gijn J. Interobserver agreement for the assessment of handicap in stroke patients. Stroke. 1988;19:604-7.

23. Cid-Ruzafa J, Damián-Moreno J. Valoración de la discapacidad física: el indice de Barthel. Rev Esp Salud Publica. 1997;71:127-37.

24. Wityk RJ, Pessin MS, Kaplan RF, Caplan LR. Serial assessment of acute stroke using the NIH Stroke Scale. Stroke. 1994;25:362-5. Erratum in: Stroke 1994; 25:1300.

25. Goldstein LB, Bertels C, Davis JN. Interrater reliability of the NIH stroke scale. Arch Neurol. 1989;46:660-2.

26. Group EQL. EuroQoL - a new facility for measurement of health -related quality of life. Health Policy. 1990;16:199-208.

27. Badía X, Roset M, Montserrat S, Herdman M, Segura A. La versión española del EuroQol: descripción y aplicaciones. Med Clin (Barc). 1999;112(supl 1):S79-86.

28. Sneew KCA, Aaronson NK, de Haan R, Limburg M. Assessing quality of life after stroke: the value and limitations of proxy ratings. Stroke. 1997;28:1541-9.

29. Cohen J. Statistical Power Analysis for the Behavioral Sciences. New York: Academic Press; 1977. p. 8.

30. Oliva-Moreno J, Lopez-Bastida J, Worbes-Cerezo M, Serrano-Aguilar P. Health related quality of life of Canary Island citizens. BMC Public Health. 2010;10:675.

31. Deyo RA, Centor RM. Assessing the responsiveness of functional scales to clinical change: an analogy to diagnostic test performance. J Chronic Dis. 1986;39:897-906.

32. Arrazola A, Beguiristain JM, Garitano B, Mar J, Elizalde B. Hospital care of cerebrovascular accident and the state of patients 12 months after. Rev Neurol. 2005:40:326-30.

33. Whiteley WN, Thompson D, Murray G, Cohen G, Lindley RI, Wardlaw J, et al. Targeting recombinant tissue-type plasminogen activator in acute ischemic stroke based on risk of intracranial hemorrhage or poor functional outcome: an analysis of the Third International Stroke Trial. Stroke. 2014;45:1000-6.

34. Hankey GJ. Long-term outcome after ischaemic stroke/transient ischaemic attack. Cerebrovasc Dis. 2003;16 Suppl 1:14-9.

35. Orfila F, Ferrer M, Lamarca R, Tebe C, Domingo-Salvany A, Alonso J. Gender differences in health-related quality of life among the elderly: the role of objective functional capacity and chronic conditions. Soc Sci Med. 2006;63:2367-80.

36. Mar J, Begiristain JM, Arrazola A. Cost-effectiveness analysis of thrombolytic treatment for stroke. Cerebrovasc Dis. 2005;20:193-200.

37. Pickard AS, Neary MP, Cella D. Estimation of minimally important differences in EQ-5D utility and VAS scores in cancer. Health Qual Life Outcomes. 2007:5:70.

38. Guyatt GH, Osoba D, Wu AW, Wyrwich KW, Norman GR, the clinical significance consensus meeting group. Methods to Explain the Clinical Significance of Health Status Measures. Mayo Clin Proc. 2002;77:371-83.

39. Ovbiagele B. Nationwide trends in in-hospital mortality among patients with stroke. Stroke. 2010;41:1748-54.

40. Lozano R, Naghavi M, Foreman K, Lim S, Shibuya K, Aboyans V, et al. Global and regional mortality from 235 causes of death for 20 age groups in 1990 and 2010: a systematic analysis for the Global Burden of Disease Study 2010. Lancet. 2012;380:2095-128.
41. Murray CJ, Vos T, Lozano R, Naghavi M, Flaxman AD, Michaud C, et al. Disability-adjusted life years (DALYs) for 291 diseases and injuries in 21 regions, 1990-2010: a systematic analysis for the Global Burden of Disease Study 2010. Lancet. 2012;380:2197-223.

42. Wiedmann S, Hillmann S, Abilleira S, Dennis M, Hermanek P, Niewada M, et al. Variations in acute hospital stroke care and factors influencing adherence to quality indicators in 6 European audits. Stroke. 2015;46:579-81.

43. Wiedmann S, Norrving B, Nowe T, Abilleira S, Asplund K, Dennis M, et al. Variations in quality indicators of acute stroke care in 6 European countries: the European Implementation Score (EIS) Collaboration. Stroke. 2012;43(2):458-63.

44. López Fernández JC, Masjuan Vallejo J, Arenillas Lara J, Blanco González M, Botia Paniagua E, Casado Naranjo I, et al. Analysis of stroke care resources in Spain in 2012: have we benefitted from the Spanish Health System's stroke care strategy? Neurologia. 2014;29(7):387-96.

45. Brea A, Laclaustra M, Martorell E, Pedragosa A. Epidemiology of cerebrovascular disease in Spain. Clin Investig Arterioscler. 2013;25:211-7.

46. Pedragosa A, Alvarez-Sabín J, Rubiera M, Rodriguez-Luna D, Maisterra O, Molina $C$, et al. Impact of telemedicine on acute management of stroke patients undergoing endovascular procedures. Cerebrovasc Dis. 2012;34(5-6):436-42.

\section{Submit your next manuscript to BioMed Central and take full advantage of:}

- Convenient online submission

- Thorough peer review

- No space constraints or color figure charges

- Immediate publication on acceptance

- Inclusion in PubMed, CAS, Scopus and Google Scholar

- Research which is freely available for redistribution 